\title{
Examining the impact of musculus palmaris longus on serve speed and on certain motoric properties in tennis players
}

\author{
Soyal M. ${ }^{1 \mathrm{BCDE}}$, Kaya M. ${ }^{2 \mathrm{ABDE}}$, Çelik N.M. ${ }^{3 \mathrm{ADE}}$ \\ ${ }^{1}$ Physical and Sport College, Istanbul Gelisim University, İstanbul, Turkey \\ ${ }^{2}$ Faculty of Sport Sciences, Erciyes University, Kayseri, Turkey \\ ${ }^{3}$ Physical and Sport College, Batman University, Batman, Turkey
}

Authors' Contribution: A - Study design; B - Data collection; C - Statistical analysis; D - Manuscript Preparation; E - Funds Collection.

\begin{abstract}
Purpose:

The aim of this study is to examine the impacts of existence or absence of musculus palmaris longus (MPL) on serve speed and certain motoric properties in the tennis players.

Material:

In the study, 25 male volunteers participated, who are playing tennis at university level and in whom the existence of musculus palmaris longus was checked. The ages of volunteers, who participate in tennis activities under licenses, vary between 18 and 25 and they have no disability or illness in the upper extremity. The experimental group $(n=7)$ is comprised of individuals, who do not have musculus palmaris longus, while the control group $(n=18)$ is comprised of individuals having musculus palmaris longus.

Results: $\quad$ The age averages of the groups participating in the study was 21, 89 2 , 246 years old for the group with musculus palmaris longus, while it was $22,00 \pm 2,517$ years old for the participants without the musculus palmaris longus; as per their average height, it was $174,94 \pm 5,713 \mathrm{~cm}$ for the group with the musculus palmaris longus, while it was $174,71 \pm 3,546 \mathrm{~cm}$ for the participants without the musculus palmaris longus; the body weight average was $70,83 \pm 5,79 \mathrm{~kg}$ for the participants with musculus palmaris longus, while it was $72,14 \pm 4,059 \mathrm{~kg}$ for the participants without the musculus palmaris longus; sports-age average was $13,00 \pm 1,645$ years for the ones with musculus palmaris longus, while it was 12 , $29 \pm 1,380$ years for the participants without musculus palmaris longus. It was determined that there was statistically significant difference for the serve speed $(p<0,001)$ and the hand flexion strength $(p<0,05)$ parameters of the participants; however, there was statistically no significant difference $(p>0,05)$ in other parameters.

Conclusions: $\quad$ As the conclusion, existence of musculus palmaris longus in tennis players positively influences the hand wrist flexion strength, however, it negatively influences the serve speed.

Keywords: musculus palmaris longus, tennis, serve speed, motoric properties.
\end{abstract}

\section{Introduction}

With the increasing expectations in the sports competitions, a need has arisen to examine and interpret in more detail the elements determining the performance. It is asserted by scientific studies that it is vital to support the relationship between the training, which is among the important components of performance, and the anatomical and kinesiological structure of the athlete. Particularly in racket sports like tennis, the opinion comes to the fore that the synchronization between the hand wrist and forearm muscles are of vital importance.

Musculus Palmaris longus (MPL) is a thin, long, and cylindrical muscle, which allows the hand to conduct flexion [1]. It helps the flexion of the fingers by stretching the aponeurosis palmaris. MPL is one of the muscles with the highest variations [2,3] Palmaris longus is one of the most changeable muscles of the body. This muscle starts from the medial epicondyle ending at the palmar aponeurosis in a tendon form $[4,5]$. This tendon, along with foot thumb long extensors, extensor indicis proprius, extensor digiti minimi, and plantaris tendon, often used as tendon graft in various reconstructive interventions at hand [6]. In a study, it was reported that, in cases bearing difficulties for standard inspection, the patient is asked to

(c) Soyal M., Kaya M., Çelik N.M., 2019

doi:10.15561/18189172.2019.0407 make a " $v$ " sign while the second and third fingers of the hand are at complete extension and the hand wrist is at flexion, and thus the PL muscle becomes visible on the flexor carpi radialis medial [7]. In the studies the absence of palmaris longus was reported as $15 \%$ [8]. In a study conducted by Gruber in 1872 on the absence of MPL with 1400 extremities, agenesis was determined as 12, $7 \%$ [9]. In our country, the first study in this issue was conducted by Karatay in 1970 [10] and the agenesis ratio was determined as $20,5 \%$ with randomly selected 1506 individuals.

The speed of the ball in a serve depends on a complex unity of interdependent factors such as anthropometric, bio-motoric, and biomechanical factors. The physical structure, strength, joint range of motion, joint speed and racket speed of the tennis player during the serve are of vital importance among these factors [11]. In a study conducted on tennis players with a good talent at serves by Cohen et al., (1994) [12]. It was determined that there was a significant relationship between the speed of the tennis ball and hand wrist flexion, shoulder flexion, and internal rotation joint range of motion.

The aim of this study is to reveal the impact of absence of musculus palmaris longus on serve speed and on some certain motoric properties of tennis players. 


\section{Material and Method}

Participants.

Forming Voluntary Groups:

The research group was comprised of 25 volunteering males, who were playing tennis at university level and in whom the existence of musculus palmaris longus was checked. The ages of volunteers, who participate in tennis activities under licenses, varied between 18 and 25 and they had no disability or illness in the upper extremity. The volunteers were informed before the study started and their approvals were gained.

Measurements of height and body weight;

A tape measure with a $0,01 \mathrm{~cm}$ precision was used in measuring the heights of the volunteers. The measurements were taken while the volunteers were barefoot. Measurements were carried out while the participants were head upright, with bare feet on the ground, the knees stretched, the heels adjacent and the body upright; the body weights were measured with barefoot and minimal clothing through a weighing scale with $0.1 \mathrm{~kg}$ precision.

Medicine ball throwing test;

For the medicine ball throwing test, the athlete was asked to stand at the starting point designated with a tape. On his knees, the athlete was asked to throw the $3-\mathrm{kg}$ medicine ball forward over his head in a throwin position. The first contact point of the medicine ball with the ground was determined. The distance between the starting point and the first spot where the ball hit the ground were measured and recorded. The better of the two trials were taken into consideration $[13,14]$

Measurement of Grasping Power;

Among the hand dynamometer measurement methods, the Baseline digital hand dynamometer was used, which was able to measure power up to $100 \mathrm{~kg}$. For the measurement of the grasping power, the dynamometer was adjusted according to the hand sizes of the subjects. The arm of the subject was held straight with a $10-15^{\circ}$ angle from the shoulder, and the maximum power measurement was applied twice for the dominant hand that the player used in tennis. The best value was recorded [15].

Flexion strength measurement of the hand;

The measurement of the hand flexion strength of the participant athletes was conducted through a device which was developed by means of the digital Aryavet brand hand scale. The measurements were conducted while the subjects were on foot. The measurement was conducted without bending the arm and without contacting it to the body with a $45^{\circ}$ angle. This process was repeated for three times for the dominant and non-dominant hand and the best value was recorded in $\mathrm{kg}$ [16].

Sports-age: the sports-ages were calculated considering the years that the volunteers obtained their licenses.

Serve speed;

The Measurement of Tennis Ball Speed; in measuring the ball speed, all of the serves were employed in a closed environment in order to control the impact of the air. The subjects warmed up until they reached their highest serve speed. 3 mins after the subjects warmed up, the test process started and they were asked to employ 5 serves at the highest speed. A radar (Stalker solo 2) was used in the measurement of the ball speed. The radar used in the measurement of ball speed was fastened up at the centre (net) line. In accordance with the rules of tennis, backhand serve was required sending the ball to the return point, and the serve was not recorded as valid if the ball was dropped out of the net or outside the service box (out). The feedbacks of the speeds were reported to the players for the highest effort. All serves were placed in the left service box (right side) for right-handed players, and in the right service box (left side) for left-handed players. All tennis players were instructed to use the straight serve technique and were evaluated by three tennis trainers. For the data analysis, the fastest $(\mathrm{km} / \mathrm{h})$ of the 5 serves scored by the players was analyzed as the maximal service (Vmax) [12].

Checking the musculus palmaris longus;

For checking the existence of the musculus palmaris longus, the subjects were asked to apply opposition between their thumb and little finger while their hand wrist was at flexion and supination; at this position, if the PL muscle became visible on the flexor carpi radialis medial than the existence of the PL muscle was accepted (Figure 1) [5].

Statistical Analysis.

In this study, Spss 25 package program was used to

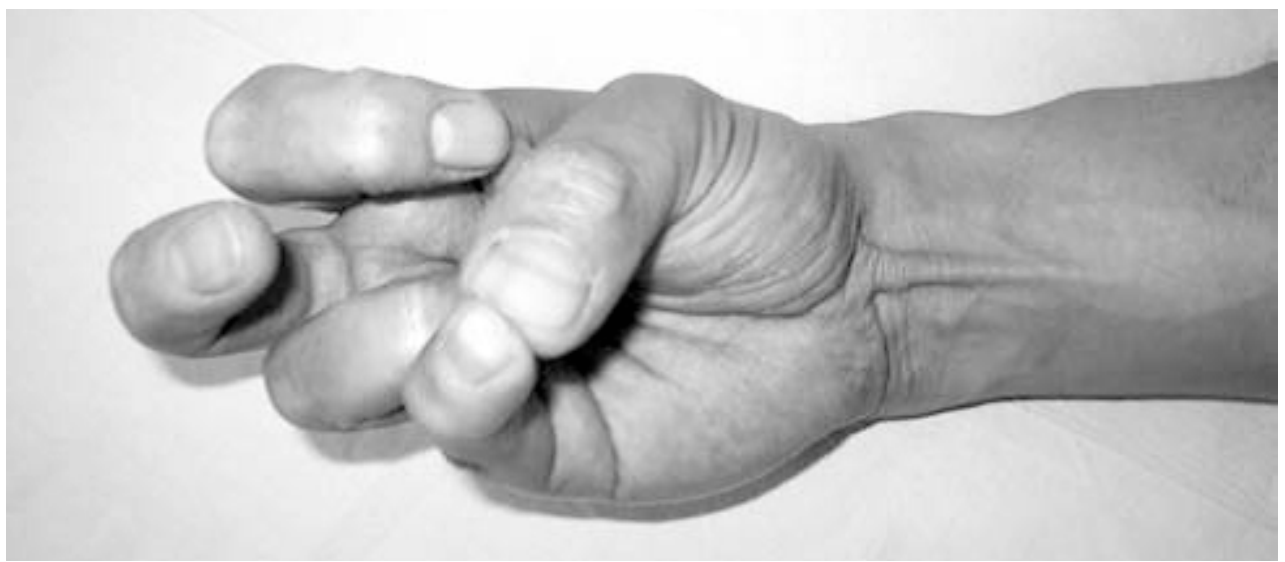

Figure 1. Demonstration of the palmaris longus muscle through the classical method. 
obtain statistical results. The mean and standard deviation of the measured and tested variables of all subjects evaluated were calculated. Independent sample $t$ test was used to compare the groups and 0.05 significance level was accepted.

\section{Results}

The absence of musculus palmaris longus was encountered only in 7 subjects out of 25 . It was determined that this muscle was absent in the dominant hands of the volunteers.

When the Table 1 was examined, it is observed that the age averages of the groups participating in the study was $21,89 \pm 2,246$ years for the group with musculus palmaris longus, while it was $22,00 \pm 2,517$ years for the participants without the musculus palmaris longus; as per their average height, it was $174,94 \pm 5,713 \mathrm{~cm}$ for the group with the musculus palmaris longus, while it was $174,71 \pm 3,546 \mathrm{~cm}$ for the participants without the musculus palmaris longus; the body weight average was $70,83 \pm 5,79 \mathrm{~kg}$ for the participants with musculus palmaris longus, while it was $72,14 \pm 4,059 \mathrm{~kg}$ for the participants without he musculus palmaris longus; sports- age average was $13,00 \pm 1,645$ years for the ones with musculus palmaris longus, while it was $12,29 \pm 1,380$ years for the participants without musculus palmaris longus

When the Table 2 was examined, it is observed that there was statistically significant difference for the serve speed $(\mathrm{p}<0,001)$ and the hand flexion strength $(\mathrm{p}<0$, 05) parameters of the participants; however, there was statistically no significant difference $(p>0,05)$ in other parameters.

\section{Discussion}

In this study, which was conducted to examine the impact of absence of musculus palmaris longus on serve speed and some certain motoric properties in tennis players, it was determined, based on the data, that there was statistically significant difference for the serve speed and the hand flexion strength parameters of the participants; however, there was statistically no significant difference in other parameters.

When the literature is examined, it is observed that there were not many previous studies conducted on musculus palmaris longus. Moreover, there was literally

Table 1. Personal properties of the individuals participating in the study.

\begin{tabular}{|c|c|c|c|c|c|}
\hline Variables & Groups & $\mathbf{n}$ & $X \pm S D$ & Minimum & Maximum \\
\hline \multirow[t]{2}{*}{ Age (Years Old) } & $\begin{array}{l}\text { Existing } \\
\text { Musculus } \\
\text { Palmaris } \\
\text { Longus }\end{array}$ & 18 & $21.89 \pm 2.246$ & 18 & 25 \\
\hline & $\begin{array}{l}\text { Absent } \\
\text { Musculus } \\
\text { Palmaris } \\
\text { Longus }\end{array}$ & 7 & $22.00 \pm 2.517$ & 19 & 25 \\
\hline \multirow[t]{2}{*}{ Height (Cm) } & $\begin{array}{l}\text { Existing } \\
\text { Musculus } \\
\text { Palmaris } \\
\text { Longus }\end{array}$ & 18 & $174.94 \pm 5.713$ & 167 & 189 \\
\hline & $\begin{array}{l}\text { Absent } \\
\text { Musculus } \\
\text { Palmaris } \\
\text { Longus }\end{array}$ & 7 & $174.71 \pm 3.546$ & 168 & 178 \\
\hline \multirow[t]{2}{*}{ Body Weight (Kg) } & $\begin{array}{l}\text { Existing } \\
\text { Musculus } \\
\text { Palmaris } \\
\text { Longus }\end{array}$ & 18 & $70.83 \pm 5.793$ & 60 & 85 \\
\hline & $\begin{array}{l}\text { Absent } \\
\text { Musculus } \\
\text { Palmaris } \\
\text { Longus }\end{array}$ & 7 & $72.14 \pm 4.059$ & 65 & 78 \\
\hline \multirow[t]{2}{*}{ Sports Age (Year) } & $\begin{array}{l}\text { Existing } \\
\text { Musculus } \\
\text { Palmaris } \\
\text { Longus }\end{array}$ & 18 & $13.00 \pm 1.645$ & 10 & 15 \\
\hline & $\begin{array}{l}\text { Absent } \\
\text { Musculus } \\
\text { Palmaris } \\
\text { Longus }\end{array}$ & 7 & $12.29 \pm 1.380$ & 10 & 14 \\
\hline
\end{tabular}


no previous study conducted on musculus palmaris longus in tennis players, which becomes a limitation for the discussion part of this study and which at the same time increases the significance of our study even more. As is known, musculus palmaris longus doesn't exist in every human being. Based on our research, it was reported in previous studies by various authors that this muscle has different anomalies [4, 17]. Some of these reported anomalies are muscle having three tops, existing as a pair, making insertions in different sites, the belly of the muscle standing distal, or having tendons at the both sides while the belly of the muscle is in the middle [16]. Some of these anomalies were reported to be creating pressure on $n$. medianus and $n$. ulnarise, or even if do not create a pressure, they cause pain in the hand wrist $[17$, 18]. In terms of performance, it is considered important for the athletes to undergo necessary medical inspections concerning this muscle in case of a pain in the wrist or forearm, which might be due to this kind of anomalies.
The main topic of our research study is to determine whether existence or absence of the musculus palmaris longus in tennis players have an impact on their serve speed or on some certain motoric properties.

Considering the distribution of the absence of MPL on the extremities, it was observed in previous studies that bilateral absence was more frequent compared to one-sided absence, and it was determined that it was more frequent on the left side among the ones having one-sided absence [9, 19]. In this study the volunteers were evaluated according to their dominant hands and the experimental group was comprised of participants with bilateral absence.

In the literature, it was reported that the absence of the PL muscle was between 5-21\% [20]. In our study, the absence of PL muscle was determined as $28 \%$. The absence frequency of the PL muscle in our study was determined to be higher compared to those of the studies from abroad. The reason behind this can be explained by

Table 2. Comparison of the grasping, ball throwing, and serve speeds of the participant individuals that were measured considering the existence and absence of the musculus palmaris longus

\begin{tabular}{|c|c|c|c|c|c|}
\hline Variables & Groups & $n$ & $X \pm S D$ & $t$ & $\mathbf{P}$ \\
\hline \multirow[t]{2}{*}{$\begin{array}{l}\text { Medicine Ball Throwing } \\
\text { (m) }\end{array}$} & $\begin{array}{l}\text { Existing } \\
\text { Musculus } \\
\text { Palmaris } \\
\text { Longus }\end{array}$ & 18 & $11.25 \pm .56$ & .749 & .466 \\
\hline & $\begin{array}{l}\text { Absent } \\
\text { Musculus } \\
\text { Palmaris } \\
\text { Longus }\end{array}$ & 7 & $11.09 \pm .44$ & & \\
\hline \multirow[t]{2}{*}{ Grasping Power (kg) } & $\begin{array}{l}\text { Existing } \\
\text { Musculus } \\
\text { Palmaris } \\
\text { Longus }\end{array}$ & 18 & $44.73 \pm 1.42$ & -.787 & .445 \\
\hline & $\begin{array}{l}\text { Absent } \\
\text { Musculus } \\
\text { Palmaris } \\
\text { Longus }\end{array}$ & 7 & $45.17 \pm 1.19$ & & \\
\hline \multirow[t]{2}{*}{ Serve Speed (km/hour) } & $\begin{array}{l}\text { Existing } \\
\text { Musculus } \\
\text { Palmaris } \\
\text { Longus }\end{array}$ & 18 & $113.52 \pm 8.82$ & -5.548 &, $000 * *$ \\
\hline & $\begin{array}{l}\text { Absent } \\
\text { Musculus } \\
\text { Palmaris } \\
\text { Longus }\end{array}$ & 7 & $130.37 \pm 5.85$ & & \\
\hline \multirow[t]{2}{*}{$\begin{array}{l}\text { Hand Flexion Strength } \\
\text { (kg) }\end{array}$} & $\begin{array}{l}\text { Existing } \\
\text { Musculus } \\
\text { Palmaris } \\
\text { Longus }\end{array}$ & 18 & $31.93 \pm 7.26$ & 2.432 & ,025* \\
\hline & $\begin{array}{l}\text { Absent } \\
\text { Musculus } \\
\text { Palmaris } \\
\text { Longus }\end{array}$ & 7 & $26.19 \pm 4.29$ & & \\
\hline
\end{tabular}

${ }^{*} p<0,05 ; *^{*} p<0,001$ 
the limited number of tennis players.

In a study, it was reported that the flexion strength applied to the hand was different among the individuals with existence and absence of the MPL. Existence of MPL increases the flexion strength of the hand in athletes. It was determined that the hand with the MPL has more flexion strength compared to the hand without the MPL. According to the findings of the same study, it was reported that the existence of the MPL muscle was an advantage in the trainings for strengthening the throwing power in basketball, handball, and volleyball branches. From this point of view, in this study, it was reported that the hand with a higher flexion strength has a vital role while shooting the basketball to the basket, during the smash in volleyball, during the shots in handball, and in racket sports (during the powerful hit of the racket to the ball) [16]. It was observed that the finding of this study that the hand flexion strength was higher in the players with the Musculus Palmaris Longus was supported by the findings of the study conducted by Özgönül et al. However, it was also observed that the finding of this study that the serve speed values of the volunteers without the Musculus Palmaris Longus were higher was not supported by the abovementioned study. It was concluded that existence of the MPL doesn't have any impact on the serve speed because of some reasons such as shoulder and back muscles have an impact on the serve speed besides the technical competence, the hit is employed by the arm as a whole, and it doesn't need hand wrist flexion during the serve in tennis.

In another study in the literature, it was reported that the existence of the PL is simply detected because of its near-surface location, long and distinct structure and that it is known that its absence doesn't weaken the fingers [21]. In our study, when the hand flexion powers of the participant tennis players with existence and absence of the Musculus Palmaris Longus are examined, it is observed that our finding was in advantage of the players with the MPL concerning the hand flexion strength. This finding of our study contradicts to the result of the abovementioned study, which can be explained by the fact that the tennis players in this group are actively dealing with other sports branches as well.

In a study conducted on examining the impact of varying ball speeds on the muscle activation properties during volleys in tennis via electromyography technique by Chow et al., (1999), [22], it was reported that high ball speed causes an increase in ball muscle activation and therefore, a hardening occurs in grasping power and wrist. In this study, the serve speeds were examined, in other words, the player hit the ball that he sends; therefore, it is suggested that further studies should be conducted on the impact of existence of Musculus Palmaris Longus on hitting performances of the players against fast balls coming from the opposite side.

In a study conducted by Ertem et al., it was determined that the right hand grasping power of the individuals with the Musculus Palmaris Longus was $47.4 \pm 7.6 \mathrm{~kg}$ and the left hand grasping power was $46.6 \pm 7.5 \mathrm{~kg}$, while it was determined that the right hand grasping power of the individuals without the Musculus Palmaris Longus was $46.7 \pm 7.0 \mathrm{~kg}$ and the left hand grasping power was $45.7 \pm 7.4 \mathrm{~kg}$, and there was statistically no significant difference between them[5]. Examining the hand grasping powers (the dominant hand was the right hand for all the volunteers) of the participants in our study, it was determined that the right hand grasping power of the individuals with the Musculus Palmaris Longus was $47.4 \pm 7.6 \mathrm{~kg}$, and the left hand grasping power was $46.6 \pm 7.5 \mathrm{~kg}$; while the right hand grasping power of the individuals without the Musculus Palmaris Longus was $46.7 \pm 7.0 \mathrm{~kg}$, and the left hand grasping power was $45.7 \pm 7.4 \mathrm{~kg}$ [5]. It is observed that these results are supported with this study.

In a study conducted by Vercruyssen et al., it was reported that existence of musculus palmaris longus was not a disadvantage [23]. In this study, the insignificant results in medicine ball throwing and grasping power values are considered to be generating from the fact that the success in these tests were not influenced from the participants with and without the musculus palmaris longus.

\section{Conclusions}

When the literature is examined, it is observed that the existence of musculus palmaris longus had no impact on grasping power, and this finding is supported by our study. It is observed that the serve speed is quite high particularly in the tennis players without musculus palmaris longus. This finding can be interpreted as existence of musculus palmaris longus negatively influence the serve speed in tennis players. As per the hand wrist flexion strength, it is observed that the players with musculus palmaris longus have better values. As the conclusion, it was considered that absence of musculus palmaris longus in tennis players have a positive impact on serve speed, and in players with musculus palmaris longus, the top spin shots will be performed better together with the impact of the hand flexion power. For further studies, it is considered that examining the impact of musculus palmaris longus on top spin shots will contribute to the sports sciences.

\section{Conflicts of interest}

The authors declare that they have no conflicts of interest. 


\section{References}

1. Ito MM, Aoki M, Kida MY, Ishii S, Kumaki K, Tanaka S. Length and width of the tendinous portion of the palmaris longus: a cadaver study of adult Japanese $J$ Hand Surg. 2001;26(4):706- 10. https://doi.org/10.1053/jhsu.2001.26026

2. Carroll CM, Pathak I, Irish J, Neligan PC, Gullane PJ. Reconstruction of total lower lip and chin defects using the composite radial forearm--palmaris longus tendon free flap. Arch Facial Plast Surg. 2000;2(1):53- 6. https://doi.org/10.1001/archfaci.2.1.53

3. Çinar C, Arslan H, Ogur S. Reconstruction of massive lower lip defect with the composite radial forearmpalmaris longus free flap: empowered static and partial dynamic econstruction. $J$ Craniofac Surg. 2007;18(1):237-41. (In Turkish ) https://doi.org/10.1097/01.scs.0000246738.76848.fe

4. Bencteux P, Simonet J, el Ayoubi L, Renard M, Attignon I, Dacher JN, et al. Symptomatic palmaris longus muscle variation with MRI and surgical correlation: report of a single case. Surg Radiol Anat 2001;23:273- 5. https://doi.org/10.1007/s00276-001-0273-x

5. Ertem K, Esenkaya İ, Elmalı N, Yoloğlu S.: Palmaris longus tendonunun bulunmama sıklığı ve yokluğunun elin kavrama ve birinci çimdikleme kuvvetlerine olan etkisi, Joint Dis Rel Surg 2007;18(3):126-129.

6. Wehbe MA, Mawr B. Tendon graft donor sites. $J$ Hand Surg 1992;17-A: 1130-2. (In Turkish ) https://doi.org/10.1016/S0363-5023(09)91079-6

7. Pushpakumar SB, Hanson RP, Carroll S. The 'two finger' sign. Clinical examination of palmaris longus (PL) tendon. $B r \quad J$ Plast Surg, 2004;57:184- 5. https://doi.org/10.1016/j.bjps.2003.11.024

8. Kocabiyik N. Morphometric analysis of the palmaris longus muscle: a fetal study. Anatomy (International Journal of Experimental and Clinical Anatomy), 2013;6-7:42-7. (In Turkish) https://doi.org/10.2399/ana.11.158

9. Reimann AF, Daseler EH, Anson BJ, Beaton LE. The palmaris longus muscle and tendon. A study of 1600 extremities. Anat Rec. 1944; 89:495-505. https://doi.org/10.1002/ar.1090890408

10.Karatay S. Musculus Palmaris Longus ve Türklerdeki Durumu. Hacettepe Tip, Cerrahi Bulteni, 1970; 3:1-9.

11.Reid M, Elliott B, Alderson, J.Shoulder joint loading in the high-performance flat and kick serves. $\mathrm{Br} \quad J \quad S p$ Med. 2007;41:884-889. (In Turkish) https://doi.org/10.1136/bjsm.2007.036657
12.Cohen DB, Mont MA, Campbell KR, Vogelstein BN, Loewy JW. Upper extremity physical faktors affecting tenis serve velocity, The American Journal of Sports Medicine, 1994; 22 (6): 746-750. https://doi.org/10.1177/036354659402200604

13.Gozzoli C, Simohamed J, El-Hebil AM. Educational Cards Kids' Athletics. IAAF. [Internet]. 2006 [updated 2006 Jun 15; cited 2018 Nov 5]. Available from: http://www.iaaf.org/ $\mathrm{mm} /$ Document/imported/37264.pdf

14.Diker G, Zileli R, Özkamçı H, Ön S.: Evaluation of Some Physiological and Biomotor Features of Young Tennis Players Journal of Sports, Exercise and training Science, 2017;3(1):25-32. (In Turkish) https://doi.org/10.18826/useeabd.296396

15.İri R, Başlamışlı A, Göksu ÖC. Investigation of Physical and Motoric Characteristics of Quick Force Training in Male Handball Players Between 18-21 Years. İ.Ü. Spor bilimleri Dergisi, 2003;11(3):47-52. (In Turkish)

16.Özgönül E, Koç H, Aycan K. Research of M. Palmarıs Longus Effect To Hand's Fexion Force, $10^{\text {th }}$ Sport Science Congress, October 23-25, Bolu/Turkey. 2008. P. 100-110. (In Turkish).

17.Baldi SV, Hug U, Jandali AR, Meyer VE. Painful tendon insertionanomalyofthepalmarislongusmuscleinaprofessional cellist. Handchir Mikrochir Plast Chir. 2005;37(6):415-7. https://doi.org/10.1055/s-2005-837698

18.Schuurman AH, van Gils AP. Reversed palmaris longus muscle on MRI: report of four cases. Eur Radiol. 2000;1:2332

19.Ceylan O, Mavi A. Distrubition of agenesis of the palmaris longus muscle in 12-18 year old age groups. Indian $J$ Med Sci, 1997; 51:156- 60 .

20.Troha F, Baibak GJ, Kelleher JC. Frequency of the palmaris longus tendon in North American Caucasians. Ann Plast Surg 1990;25:477-8. https://doi.org/10.1097/00000637-199012000-00008

21.Sebastin SJ, Lim AYT, Wong HW., Clinical assessment of absence of the palmaris longus and its association with other anatomical anomalies. A Chinese population study. Ann Acad Med Singapore; 2006, 35:249-53.

22. Chow JW, Carlton LG, Lim Y-T, Shim J-H, Chae W-S, Kuenster AF. Muscle activation during the tennis volley. Medicine \& Science in Sports \& Exercise, 1999;31:846-54. https://doi.org/10.1097/00005768-199906000-00013

23.Vercruyssen J, Scafoglieri A, Cattrysse E. The Impact of Palmaris Longus Muscle on Function in Sports: An Explorative Study in Elite Tennis Players and Recreational Athletes, J. Funct. Morphol. Kinesiol. 2016, 1, 167- 182. https://doi.org/10.3390/jfmk1020167 


\section{Information about the authors:}

Soyal M.; (Corresponding author); http://orcid.org/0000-0001-6528-0275; mehmetsoyal3838@hotmail.com; Physical and Sport College, Istanbul Gelisim University; Cihangir, J. Kom. Er Hakan Öner Sk. No:1, 34310 Avcılar/Istanbul, Turkey.

Kaya M.; mustafakayaerciyes@gmail.com; http://orcid.org/0000-0002-2438-2678; Faculty of Sport Sciences, Erciyes University; Yenidoğan Mahallesi Turhan Baytop Sokak No:1 38280 TALAS / KAYSERi, Turkey.

Çelik N.M.; http://orcid.org/0000-0001-6403-6262; nmcelik42@hotmail.com; Physical and Sport College, Batman University; 72000 Merkez 72, 060 Batman Merkez/Batman, Turkey.

Cite this article as:

Soyal M., Kaya M, Çelik NM. Examining the impact of musculus palmaris longus on serve speed and on certain motoric properties in tennis players. Pedagogics, psychology, medical-biological problems of physical training and sports, 2019;23(4):202-208.

https://doi.org/10.15561/18189172.2019.0407

This is an Open Access article distributed under the terms of the Creative Commons Attribution License, which permits unrestricted use, distribution, and reproduction in any medium, provided the original work is properly cited (http://creativecommons.org/licenses/by/4.0/deed.en).

Received: 08.05.2019

Accepted: 12.06.2019; Published: 29.08.2019 